\title{
Nanostructured Epoxy/POSS composites: Enhanced Materials for High Voltage Insulation Applications
}

\author{
Thomas Heid \\ École de technologie supérieure (ETS) \\ 1100 Notre-Dame Street West, Montreal, QC, H3C 1K3 Canada \\ Michel Fréchette \\ Institut de Recherche d'Hydro-Québec (IREQ) \\ 1800 Lionel-Boulet Blvd., Varennes, QC, J3X 1S1, Canada \\ and Eric David \\ École de technologie supérieure (ETS) \\ 1100 Notre-Dame Street West, Montreal, QC, H3C 1K3 Canada
}

\begin{abstract}
In this study, the dielectric and thermal properties of nanostructured epoxy/POSS (Polyhedral Oligomeric Silsesquioxanes) composites were investigated, using a reactive Triglycidylisobutyl-POSS (TGIB-POSS) additive from 1 up to $10 \mathrm{wt} \%$. POSS has been successfully dispersed at a molecular level for low content composites, which show a remarkably improved resistance to corona discharges, with up to $60 \%$ less eroded sample volume, along with significantly increased dielectric breakdown strengths and thermal conductivities. Epoxy/POSS composites containing $5 \mathrm{wt} \%$ and more of the POSS additive exhibit agglomerations, which have been observed by SEM. Furthermore, dielectric spectroscopy revealed additional interfacial loss peaks for such composites containing $5 \mathrm{wt} \%$ POSS and more, in addition to the $\alpha$ - and $\beta$-peaks known for epoxy.
\end{abstract}

Index Terms - AC breakdown strength, dielectric spectroscopy, epoxy, electrical discharge, interface, polymer composites, POSS, surface erosion, thermal conductivity.

\section{INTRODUCTION}

EPOXY resins are an important dielectric material in the high voltage insulation industry, and they are widely used in insulation systems for bushings, rotating machines and cable terminations, to name a few. However, as an organic material, it is prone to degradation due to electrical discharges and usually features rather low thermal conductivities, which can constitute a limiting factor for power ratings. These deficient properties have been counteracted in the past by the addition of micrometric inorganic filler materials, such as silica, which can render the resulting composite more resilient to electrothermal stresses and improve parameters such as the thermal conductivity.

In the last decade though, much has been reported about a novel class of dielectric materials, namely polymer nanocomposites or nanodielectrics, which feature nanometric filler particles $[1,2]$. However, such nanodielectrics can only unfold their full potential, when good dispersion and distribution of those filler particles within the matrix are achieved. Albeit, due to the incompatibility of inorganic particles with the organic polymer, dispersion and distribution are regularly compromised, resulting in agglomerations of nano particles, often leading to agglomerates with submicrometric or micrometric dimensions. In order to enhance the interaction between inorganic filler particles and the organic matrix, and hence, improve the dispersion of such particles in polymers, their functionalization has become rather common. Surface treatments with coupling agents, such as silane [3-5], or more complex processes, including grafting organic brushes on particle surfaces [6], have been explored with varying degrees of success.

As an alternative to nanometric silica, Polyhedral Oligomeric Silsesquioxanes (POSS) could be of interest for electrical insulation applications, as it is a hybrid material, consisting of an inorganic silica-like core surrounded by organic side-groups. These organic groups can be either reactive or non-reactive and therefore offer compatibility with a multitude of polymers, depending on the specific organic side-group configuration. POSS, being a hybrid inorganicorganic material, further combines the beneficial material properties of ceramics, such as inertness and electrical 
insulating properties, with the processability of polymers. It was previously denoted as a "Nano-building-block", because of its crystalline structure [7,8], enabling POSS to organize a polymeric matrix through its reactive groups on a nanometric scale. POSS molecules, commonly with sizes below $2 \mathrm{~nm}$, are assumed to be able to dissolve within a polymer without forming agglomerations known from conventional nanoparticles [9].

The successful incorporation of POSS into epoxy has been shown to significantly improve the composite's dielectric performance, in terms of corona resistance [10-12] and dielectric breakdown strengths [13-15]. Furthermore, higher thermal stabilities of POSS composites have been reported in $[8,16]$, as well as improved thermo-mechanical properties of such nanostructured materials [7].

The aim of this study was to investigate the dielectric and thermal properties of epoxy/POSS composites, by incorporating a reactive Triglycidylisobutyl-POSS, which we intended to disperse at a molecular level within the matrix.

\section{MATERIALS AND SAMPLE PREPARATION}

DER332 epoxy resin (DOW Chemicals) and Jeffamine D230 curing agent (Huntsman Corp.) were used as the base epoxy system in a ratio of 1000:344 parts (epoxy to curing agent). Liquid Triglycidylisobutyl-POSS (Hybrid Plastics) was used as an additive to fabricate composites. Triglycidylisobutyl-POSS (TGIB-POSS) has three monodirectionally oriented epoxy groups which are attached to the cage-like silica core (see Figure 1). These epoxy groups are compatible with those of the epoxy system used and can therefore form covalent bonds with the matrix, as schematically shown in Figure 1 . Due to the fact that each TGIB-POSS molecule features three additional epoxy groups that will consume curing agent during the reticulation process, a distinct stoichiometric ratio for each epoxy/POSS composite was established, in order to match the amount of reactive epoxy groups with the amine groups of the curing agent within the composite.

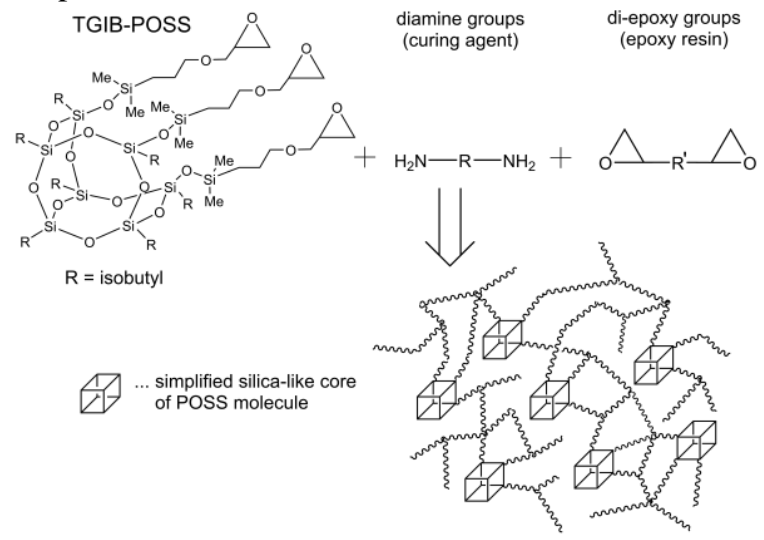

Figure 1. Proposed reaction of TGIB-POSS with curing agent and epoxy resin with the formation of covalent bonds, and hence, forming a nanostructured epoxy/POSS network.
During the compounding process, the liquid TGIB-POSS, whose viscosity is similar to that of the epoxy system, was dispersed in the epoxy resin using a magnetic stir on a hot plate at $40{ }^{\circ} \mathrm{C}$. Subsequently the curing agent was added to the mixture. The complete mixing procedures were conducted under vacuum, in order to ensure proper degassing of the liquid composites before they were cast in stainless steel molds. All test specimens were cured for six hours at $100{ }^{\circ} \mathrm{C}$ under vacuum, followed by a gradient cool down to ambient temperature. A release agent (QZ13) was applied on the mold before the epoxy was cast to facilitate the removal of the samples after the curing process. Subsequently, the samples were post-cured for 12 hours at $130{ }^{\circ} \mathrm{C}$, also under vacuum. More details about the fabrication process and the stoichiometry can be found in [17].

Along with neat epoxy resin specimens, epoxy/POSS composites with TGIB-POSS contents of 1, 2.5, 5 and $10 \mathrm{wt} \%$ were fabricated. The POSS composites are further referred to as e.g. ePOSS $1 \mathrm{wt} \%$, for the epoxy/POSS composite containing $1 \mathrm{wt} \%$ of TGIB-POSS, and so on.

\section{EXPERIMENTAL METHODS}

\subsection{MICROSTRUCTURE ANALYSIS}

The test specimens were mounted in epoxy resin and subsequently polished with grain sizes down to $50 \mathrm{~nm}$ to assure a smooth sample surface for Scanning Electron Microscope (SEM) observations. A TM3030 tabletop SEM (Hitachi High Technologies America) was used for low magnification pictures $(\mathrm{x} 5 \mathrm{k}$ ), whereas a SU-70 high resolution SEM (Hitachi High Technologies America) was used for micrographs with magnifications of $x 20 \mathrm{k}$ and $\mathrm{x} 50 \mathrm{k}$, to further investigate some features found on the composites with higher POSS contents.

\subsection{DIFFERENTIAL SCANNING CALORIMETRY}

Glass transition temperatures were measured by Differential Scanning Calorimetry (DSC) with a heat flow calorimeter (Q20, TA Instruments) on samples which had not previously been exposed to the thermal post-treatment. Each sample was subjected to two thermal cycles with a heating rate of $10{ }^{\circ} \mathrm{C} / \mathrm{min}$ from $20^{\circ} \mathrm{C}$ to $250^{\circ} \mathrm{C}$, followed by a gradual cool down to $20{ }^{\circ} \mathrm{C}$ at $10{ }^{\circ} \mathrm{C} / \mathrm{min}$. The glass transition temperatures $\mathrm{T}_{\mathrm{g}}$ were obtained from the second heating cycle to ensure no thermal history of the samples.

\subsection{AC BREAKDOWN STRENGTH}

The dielectric breakdown strength was measured based on the ASTM D 149 standard [18]. Samples were immersed in transformer oil (Luminol TR-i) and placed between two symmetrical ball tip electrodes with diameters of $4 \mathrm{~mm}$. The short-term test was used, where a $60 \mathrm{~Hz}$ voltage with a ramp rate of $2 \mathrm{kV} / \mathrm{s}$ was applied between the electrodes until breakdown occurred. On each sample type, 15 breakdowns 
were performed, after which the ball tips were exchanged and replaced with new ones to avoid pitting. The breakdown test specimens had an average thickness of $130 \mu \mathrm{m} \pm 5 \%$.

\subsection{RESISTANCE TO CORONA DISCHARGES}

To evaluate the resistance to corona discharges, each sample was subjected to partial discharges (PD) using a point-to-plane geometry operated in open air. A sinusoidal voltage of $4 \mathrm{kV}_{\mathrm{RMS}}$ at a frequency of $300 \mathrm{~Hz}$ was applied between the high voltage rod electrode, bearing a $4 \mathrm{~mm}$ diameter tungsten carbide ball tip, and the ground electrode. The samples were placed centrically on the ground electrode framed by an acrylic base plate, with the tip of the rod electrode facing the sample surface. The high voltage electrode rod and the sample surface were separated by a $200 \mu \mathrm{m}$ air gap (see Figure 2). All test specimens were exposed to electrical discharges for a duration of 30 hours, which is equal to exposures for 150 hours at $60 \mathrm{~Hz}$ and 180 hours at $50 \mathrm{~Hz}$ equivalent time, respectively.

The resistance to erosion due to corona discharges was subsequently evaluated by the use of a mechanical profilometer, based on the eroded volume calculated from the obtained data. The values of the eroded sample volumes can thus be seen as inverse reference values of the resistance to partial discharge. Before the samples were analyzed with the profilometer, they were carefully cleaned in an ultrasonic bath in order to remove the debris caused by the PD.

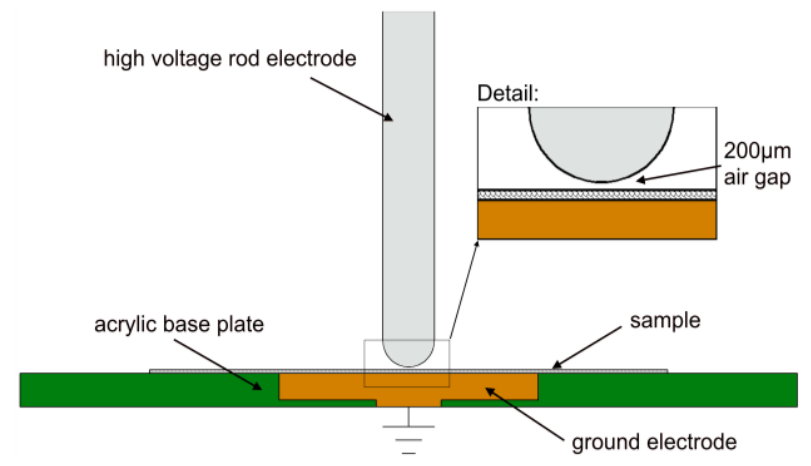

Figure 2. Schematic of point-to-plain setup for corona resistance experiment

\subsection{THERMAL CONDUCTIVITY}

The thermal conductivity was obtained with a DTC-25 guarded heat flow meter (TA Instruments) in accordance with the ASTM E 1530 standard [19]. Test specimens with $50.8 \mathrm{~mm}$ ( 2 inches) diameter were subsequently placed between the upper heating plate and the lower cooling plate of the device. A pressure of 20 psi applied on the upper plate ensured intimate contact between the sample, the heating and the cooling plates. A heat flux transducer in the lower plate measured the heat flow $Q$ through the sample. The thermal conductivity $\lambda$ is defined by (2), with the sample surface A, its thickness $t$ and the temperature drop over the sample volume $\Delta \mathrm{T}$. The measurements were conducted for a medium sample temperature of $25^{\circ} \mathrm{C}$. In order to assure the thermal stability of all test specimens during the measurements, each sample was left inside the test chamber for two hours before the thermal conductivity values were obtained.

$$
\lambda=\frac{Q / A}{\Delta T / t}
$$

\subsection{DIELECTRIC SPECTROSCOPY}

The frequency- and temperature-dependent dielectric responses of the samples were obtained by Broadband Dielectric Spectroscopy (BDS, Novocontrol) for a temperature range from $20{ }^{\circ} \mathrm{C}$ to $100{ }^{\circ} \mathrm{C}\left( \pm 0.1{ }^{\circ} \mathrm{C}\right)$, in several distinct isothermal steps. The test specimens were subjected to an excitation voltage of $1 \mathrm{~V}$ with a frequency ranging from $0.1 \mathrm{~Hz}$ to $1 \mathrm{MHz}$. The BDS measurements were performed on $40 \mathrm{~mm}$ diameter samples on a parallel plate electrode setup. The complex permittivity $\varepsilon^{*}$ as given in (1) was retrieved, with the real permittivity $\varepsilon^{\prime}$ representing the storage part, and $\varepsilon^{\prime \prime}$ the imaginary or dielectric loss part.

$$
\varepsilon^{*}(f, T)=\varepsilon^{\prime}(f, T)-j \varepsilon^{\prime \prime}(f, T)
$$

\section{EXPERIMENTAL RESULTS AND DISCUSSION}

\subsection{MICROSTRUCTURE ANALYSIS}

In Figure 3, the SEM micrographs of neat epoxy and the POSS-composites are presented. The left column shows the microstructure obtained with low magnification $(\mathrm{x} 5 \mathrm{k})$ on the TM3030 SEM. The next two columns represent SEM micrographs obtained with the high resolution Hitachi SU-70 microscope using $\mathrm{x} 20 \mathrm{k}$ and $\mathrm{x} 50 \mathrm{k}$ magnification, respectively.

For the ePOSS $1 \mathrm{wt} \%$ and ePOSS $2.5 \mathrm{wt} \%$ composites (Figure $3 \mathrm{~b}$ and Figure $3 \mathrm{c}$ ), the micrographs obtained up to a magnification of $\times 50 \mathrm{k}$ did not show any particular trace of the presence of POSS additive, and hence, the revealed microstructures resemble those obtained for the neat epoxy (Figure 3a). The POSS additive thus appears to be dispersed into the epoxy matrix at a molecular level or to very small agglomerates of less than $10 \mathrm{~nm}$ if any, which allows us to consider these specific materials as actual nanocomposites.

However, for the composites with higher filler contents, viz. ePOSS 5wt\% (Figure 3d) and ePOSS 10wt\% (Figure 3e), agglomerations of submicrometric dimensions $(<1 \mu \mathrm{m})$ were found. Further, both the size and the occurrence of these agglomerated structures increased with the POSS content.

\subsection{DIFFERENTIAL SCANNING CALORIMETRY}

The resulting graphs obtained from the DSC experiments are presented in Figure 4. The derived glass transition temperatures $T_{g}$ are summarized in Table 1. It was found that incorporating POSS into the epoxy matrix led to a slight diminishment of $\mathrm{T}_{\mathrm{g}}$ for all composites, compared to the neat polymer. The highest difference was found for the ePOSS $10 \mathrm{wt} \%$ composite, which exhibited a glass transition temperature of almost $6{ }^{\circ} \mathrm{C}$ lower than that of neat epoxy. 

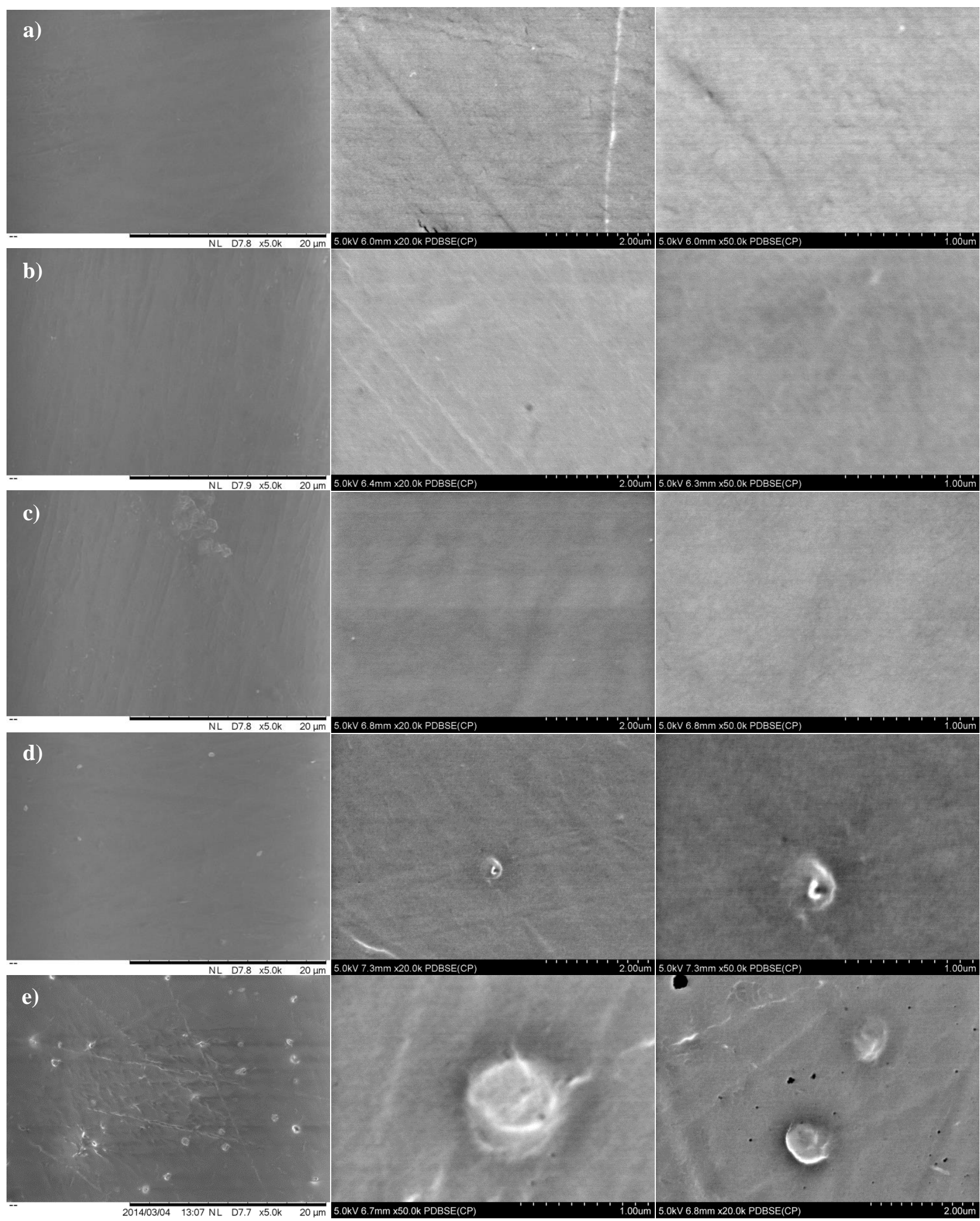

Figure 3. SEM micrographs with increasing magnification from left to right, for a) neat epoxy, b) ePOSS $1 \mathrm{wt} \%$, c) ePOSS $2.5 \mathrm{wt} \%$, d) ePOSS $5 \mathrm{wt} \%$ and e) ePOSS $10 \mathrm{wt} \%$. 


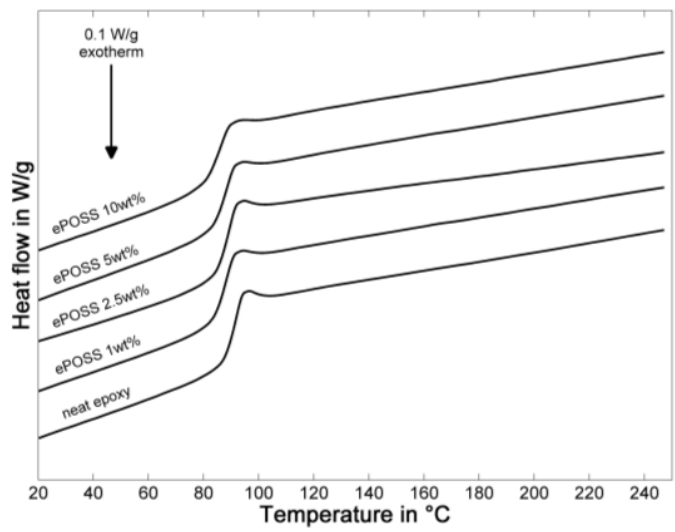

Figure 4. Overlaid DSC curves from the second thermal cycles

It is common understanding that $\mathrm{T}_{\mathrm{g}}$ is closely related to the mobility of the molecular chains of the epoxy network. The mobility of the chains will further depend on factors such as the degree of cross-linking, chain lengths, flexibility of sidegroups and chains, as well as free volume, as has been elaborated in detail in this extensive review [20]. Considering the slight decrease in $\mathrm{T}_{\mathrm{g}}$ for the POSS composites compared to the neat polymer, it is assumed that the cross-linking of the epoxy matrix is hindered in the presence of Triglycidylisobutyl-POSS. Additionally, the mono-directional alignment of epoxy groups on these particular POSS molecules might lead to shorter polymer chains, given that the chain "growth" during the cross-linking process is limited to one side of the TGIB-POSS molecule. Also, auto cross-linking between TGIB-POSS molecules themselves could further contribute to the reduction of chain lengths and cross-linking degree of the resulting epoxy/POSS network. Lastly, it should be mentioned that for the composites containing $5 \mathrm{wt} \%$ and $10 \mathrm{wt} \%$, it is possible that the involved POSS molecules in the agglomerates shown by the SEM micrographs (see Figure 3d and 3e), will not, or not completely react with hardener molecules. This would lead to free volume due to excess hardener in those composites with high POSS content, which would support the lowest values of $\mathrm{T}_{\mathrm{g}}$ for the ePOSS $10 \mathrm{wt} \%$ composite.

Table 1. Glass transition temperatures of neat epoxy and TGIB-POSS composites.

\begin{tabular}{c|c}
\hline Sample type & $\mathrm{T}_{\mathrm{g}}$ in ${ }^{\circ} \mathrm{C}$ \\
\hline Neat epoxy & 92.0 \\
ePOSS 1wt $\%$ & 88.6 \\
ePOSS $2.5 \mathrm{wt} \%$ & 89.6 \\
ePOSS 5wt\% & 88.6 \\
ePOSS 10wt $\%$ & 86.5 \\
\hline
\end{tabular}

\subsection{AC BREAKDOWN STRENGTH}

The obtained AC breakdown (BD) data were treated by the two-parameter Weibull distribution in accordance with the IEEE 930 standard [21] in order to evaluate the breakdown strengths of the test specimens. In Figure 5, the Weibull plots are depicted, and the corresponding Weibull parameters $\alpha$ and $\beta$ are summarized in Table 2. The scale parameter $\alpha$ represents

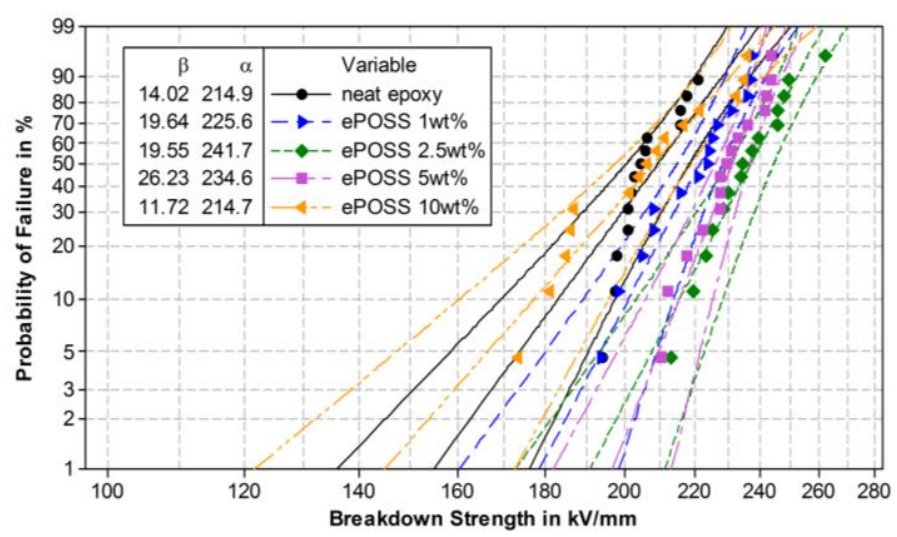

Figure 5. Weibull plot of breakdown data with $95 \%$ confidence intervals

the breakdown strengths in $\mathrm{kV} / \mathrm{mm}$ at which $62.3 \%$ of the samples experienced electric $\mathrm{BD}$, while the shape parameter $\beta$ is an inverse measure for the scatter of the BD data, meaning the higher it is, the lower the variation of the data to the Weibull distribution.

Compared to neat epoxy, which had a BD strength of $214.9 \mathrm{kV} / \mathrm{mm}$, all POSS composites, with the exception of ePOSS 10wt\%, exhibited significant increase in BD strength. The highest BD value was found for ePOSS $2.5 \mathrm{wt} \%$ $(241.7 \mathrm{kV} / \mathrm{mm})$, followed by ePOSS $5 \mathrm{wt} \%(234.6 \mathrm{kV} / \mathrm{mm})$ and ePOSS $1 \mathrm{wt} \% \quad(225.6 \mathrm{kV} / \mathrm{mm})$, whereas the $10 \mathrm{wt} \%$ composite $(214.7 \mathrm{kV} / \mathrm{mm})$ would perform just as neat epoxy. Thus, it seems there is an optimal TGIB-POSS content around $2.5 \mathrm{wt} \%$, where this POSS additive is still homogeneously dispersed within the epoxy at a molecular level, without showing agglomerations. With a further increase of filler content, the presence of TGIB-POSS agglomerations, as observed by SEM (see Figure 3), will consecutively counteract the beneficial effect of POSS. Those agglomerations will cause local electric field enhancements, which subsequently lead to higher electric stress in the vicinity of agglomerates, and further results in a decrease of the $\mathrm{BD}$ strength for the composites, until the amount and size of agglomerations have completely nullified the POSS contribution as in the case of the $10 \mathrm{wt} \%$ composite.

Previous studies have shown increased BD strengths for epoxy composites with up to $2.5 \mathrm{wt} \%$ nano-silica, while incorporation of larger contents resulted in decreased BD values in comparison with the neat epoxy [22,23]. This could most likely be attributed to conductive interfacial layers forming around silica nano-particles due to the hydrophilic nature of silica, creating conductive paths [24], and thus, corrupting the BD strength of such composites.

Table 2. Weibull parameters as obtained from Figure 5

\begin{tabular}{c|c|c}
\hline Sample type & $\begin{array}{c}\alpha \text { in } \\
\mathrm{kV} / \mathrm{mm}\end{array}$ & $\beta$ \\
\hline Neat epoxy & 214.9 & 14.02 \\
ePOSS 1wt\% & 225.6 & 19.64 \\
ePOSS 2.5wt\% & 241.7 & 19.55 \\
ePOSS 5wt\% & 234.6 & 26.23 \\
ePOSS 10wt\% & 214.7 & 11.72 \\
\hline
\end{tabular}


The hydrophilicity of silica results from the formation of silanol groups at the silica particle surface [25]. By using reactive TGIB-POSS molecules in our study, where organic groups surround the silica core, the resulting composites are not subject to the phenomenon of conductive paths around the filler. Thus, significant improvements of the dielectric strength of the resulting TGIB-POSS composites, as compared to neat epoxy, could be also achieved for comparably higher filler contents. Even more so, when agglomerations of POSS molecules can be avoided at higher filler loadings, as presented in one of our recent studies [14].

\subsection{RESISTANCE TO CORONA DISCHAGE}

The results of the surface erosion experiment based on the respective eroded sample volumes after exposure to PD for 30 hours are presented in Figure 6. A decrease of eroded sample volume can be associated with an increase in resistance to electrical discharges. The experiment showed remarkable improvements in resistance to electrical discharge of all POSS composites, as compared to the neat polymer. With a $60 \%$ and $59 \%$ reduction in ablated material, for ePOSS $1 \mathrm{wt} \%$ and ePOSS $2.5 \mathrm{wt} \%$ respectively, the low content POSS composites revealed the best resistance to electrical discharges among all test specimens. With further increases of the POSS content, a continuous diminishment of resistance to PD was however noted for the resulting POSS composites with 5 and $10 \mathrm{wt} \%$ additive. This worsening of performance should be attributed to the occurrence of cumulative agglomerations with increasing POSS contents, as observed by SEM for ePOSS 5wt $\%$ and ePOSS $10 \mathrm{wt} \%$ composites, and shown in Figure $3 \mathrm{~d}$ and Figure $3 \mathrm{e}$. Such agglomerations cause local electric field enhancements, which subsequently lead to locally increased electric and thermal stresses of the composite, resulting in intensified erosion of the surrounding organic matrix.

Similar results for improved corona resistance of epoxy composites featuring inorganic nanofillers such as silica have been reported in the past [26-28]. However, in some cases, very high nano-silica contents of $26 \mathrm{wt} \%$ and above [27] were needed to attain improvements comparable to those observed in this study, by incorporating $1 \mathrm{wt} \%$ of TGIB-POSS in epoxy. Thus, it is assumed that by dispersing POSS at a molecular level in epoxy, and because of the formation of covalent bonds

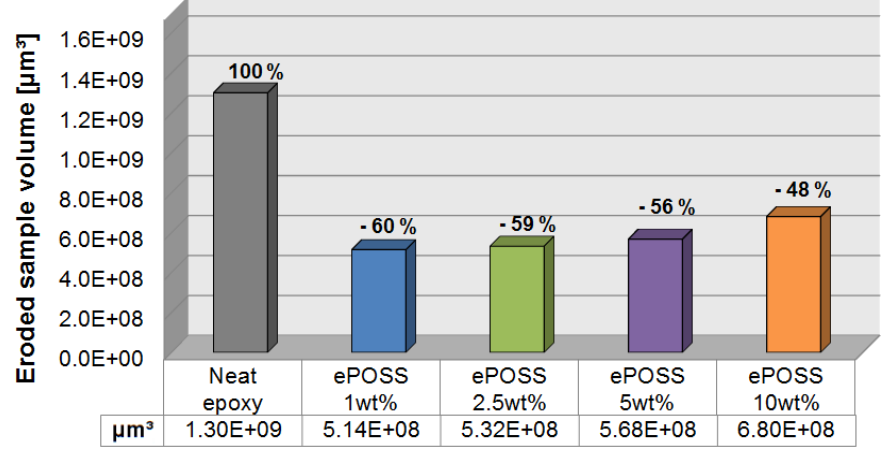

Figure 6. Evaluation of resistance to electrical discharges based on eroded sample volume after 30 hours of exposure to PD between the POSS molecules with their inorganic cores and the epoxy matrix, the resulting change of morphology, and hence, the nanostructuration of the respective composite, gives rise to the significant resistance to corona discharges for the ePOSS $1 \mathrm{wt} \%$ and ePOSS $2.5 \mathrm{wt} \%$. Coherent results with a different reactive POSS additive have been recently published in [12].

\subsection{THERMAL CONDUCTIVITY}

The thermal conductivities were measured twice on each sample type, while considering that the reproducibility of the used method used may vary by approximately $5 \%$. Further, the respective average values of thermal conductivities from those two measurement series were taken for the following discussion. The experimental results are displayed in Figure 7.

It was found, that addition of TGIB-POSS in the epoxy matrix resulted in an increase in thermal conductivities of approximately $10 \%$ for the respective composites with up to 5 wt $\%$ POSS content. The highest thermal conductivities were exhibited by both ePOSS $1 \mathrm{wt} \% \quad(0.159 \mathrm{~W} / \mathrm{m} \cdot \mathrm{K})$ and ePOSS $2.5 \mathrm{wt} \% \quad(0.159 \mathrm{~W} / \mathrm{m} \cdot \mathrm{K})$, followed by ePOSS $5 \mathrm{wt} \%$ $(0.158 \mathrm{~W} / \mathrm{m} \cdot \mathrm{K})$. However, ePOSS $10 \mathrm{wt} \%(0.149 \mathrm{~W} / \mathrm{m} \cdot \mathrm{K}) \mathrm{did}$ not reveal a significant change in thermal conductivity, as compared to the neat polymer $(0.145 \mathrm{~W} / \mathrm{m} \cdot \mathrm{K})$.

It is well established that thermal conduction in solids is based on phonons (lattice vibrations) [29, 30]. Phonon scattering, which appears at either particle-particle or particlematrix interfaces, or at the interfaces of the amorphous structure in epoxy resins itself [29], lead to attenuation of the thermal conductivity within a material. As a consequence, the addition of low contents (i.e. $1 \mathrm{wt} \%$ ) of high thermally conductive filler was deemed insufficient for significant enhancements of the thermal conductivities of the resulting composites, as indicated in several studies [31-33].

However, it was established in [29] that creating ordered, crystalline-like structures on a nanometric level within epoxy resins, which are characterized by their amorphous structure, would cause a diminishment of phonon scattering, and hence, significantly improve the thermal conductivity of the polymer.

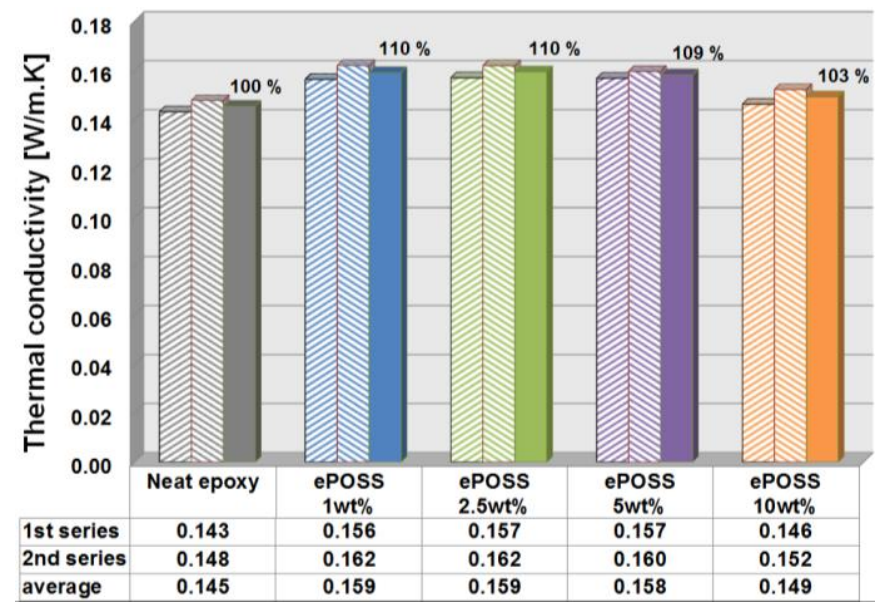

Figure 7. Evaluation of thermal conductivities for the test specimens, with the first and second measurement series plotted as dashed columns and the respective average values in solid columns 


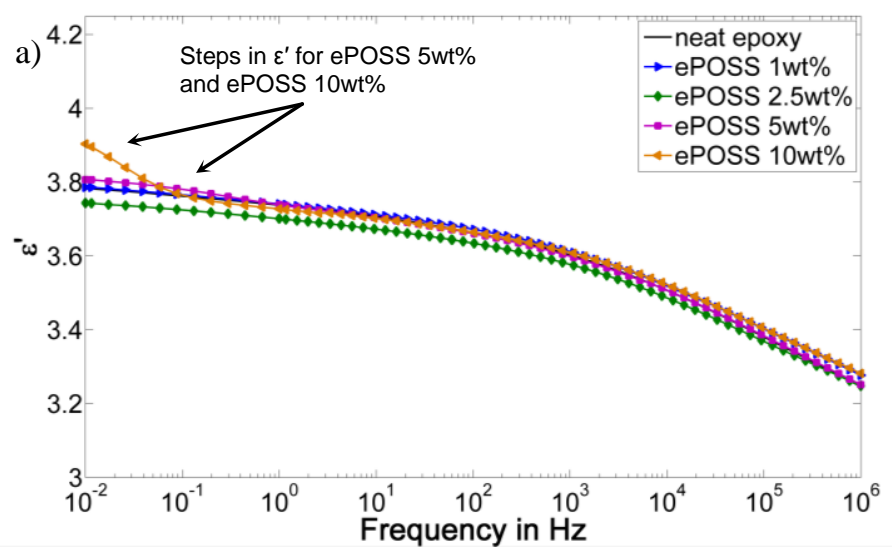

Figure 8. Dielectric responses at $20^{\circ} \mathrm{C}$ and $1 \mathrm{~V}$ of neat epoxy and the TGIB-POSS

Accordingly, by adding POSS in the epoxy resin, which forms covalent bonds with the epoxy matrix, we succeeded in nanostructuring the resulting composites, which further resulted in reduced phonon scattering within the composite. In conclusion, the thermal conductivity of the POSS composites could be improved as compared to neat epoxy.

Nevertheless, there seems to be a threshold limit in the case of TGIB-POSS, due to agglomerations seen for the $5 \mathrm{wt} \%$ and especially the $10 \mathrm{wt} \%$ POSS composites. These agglomerations cause an augmentation of phonon scattering at matrix-particle interfaces, and hence, consecutively nullify the effect of nanostructuration. Consequently, this results in more or less equivalent thermal conductivities of ePOSS $1 \mathrm{wt} \%$, ePOSS $2.5 \mathrm{wt} \%$ and ePOSS $5 \mathrm{wt} \%$. Moreover, in the case of ePOSS $10 \mathrm{wt} \%$, the numerous agglomerations might cause pronounced phonon scattering, which suppresses the beneficial effect seen for the composites with lower TGIB-POSS contents.

\subsection{DIELECTRIC SPECTROSCOPY}

The dielectric responses obtained at $20{ }^{\circ} \mathrm{C}$ for all the investigated materials are presented in Figure 8 . Both the real part of the complex permittivity (Figure 8a) and its imaginary component (Figure 8b) show that all composites exhibit dielectric responses similar to that of neat epoxy for power frequencies and above. For lower frequencies though, additional interfacial loss peaks were found for ePOSS $5 \mathrm{wt} \%$ and ePOSS 10wt\% (Figure 8b), being more pronounced for the $10 \mathrm{wt} \%$ composite. The corresponding steps in real permittivity could also be seen for lower frequencies in Figure 8a. However, ePOSS $1 \mathrm{wt} \%$ and ePOSS $2.5 \mathrm{wt} \%$ did not reveal such interfacial loss peaks, and hence, their dielectric responses are similar to that of neat epoxy.

The appearing interfacial loss peaks found for the composites containing 5 or $10 \mathrm{wt} \%$ POSS can be linked to the aforementioned agglomerations observed using SEM microscopy, as presented in Figure $3 \mathrm{~d}$ and Figure 3e. These agglomerations give rise to interfacial polarization for the composites with high filler content. This is further supported by the lack of an additional loss peak for the 1 and $2.5 \mathrm{wt} \%$ composites, as well as by the microstructure analysis where no

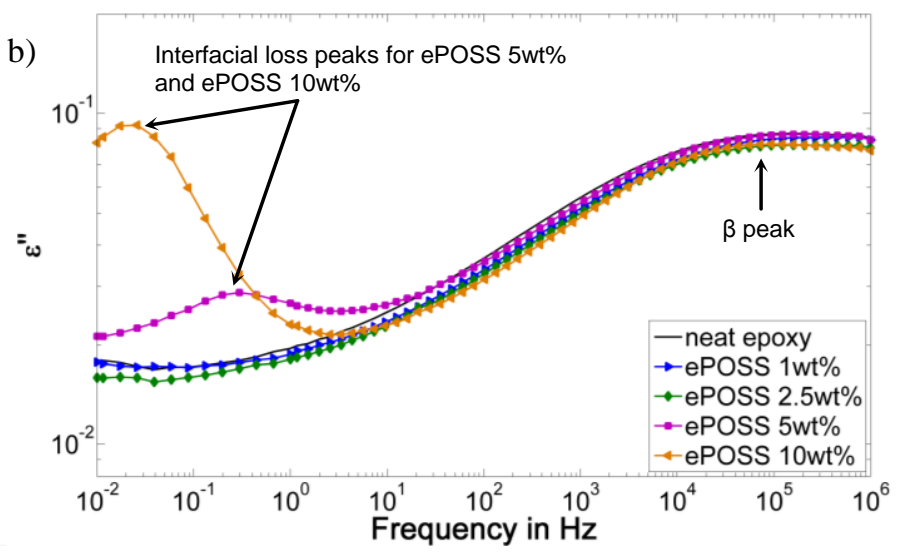

agglomerations were found for these two composites (Figures $3 \mathrm{~b}$ and $3 \mathrm{c}$ ). It therefore seems analogous to the results already presented in the previous subsections, that for low TGIB-POSS contents a good dissolution in epoxy is possible, allowing a dispersion of POSS at a molecular level. Consequently, no additional interfacial polarization occurs [34].

Figures $9 \mathrm{a}$ to $9 \mathrm{e}$ show the temperature- and frequencydependent dielectric response of all test specimens. The $\alpha$ - and $\beta$-relaxation peaks could be located for neat epoxy and the epoxy/POSS composites, for both the real and imaginary parts of the complex permittivity. In amorphous polymers, the $\alpha$-relaxation is correlated to relaxation processes of the main polymer backbone due to chain movement as a result of the glass transition phenomenon. The $\beta$-peak however, is associated with secondary relaxation processes due to local crankshaft movements of hydroxyl ether groups in the case of epoxy resin [35].

For all investigated materials, the $\beta$-peak was located for temperatures below $80^{\circ} \mathrm{C}$, in the vicinity of $100 \mathrm{kHz}$. The $\alpha$-peak was found at $100{ }^{\circ} \mathrm{C}$, with a loss maximum around $100 \mathrm{~Hz}$ for neat epoxy, ePOSS $1 \mathrm{wt} \%$, ePOSS $2.5 \mathrm{wt} \%$ and ePOSS $5 \mathrm{wt} \%$ (see Figures 9a' to 9d'). With the incorporation of $10 \mathrm{wt} \%$ POSS, the $\alpha$-peak was shifted slightly towards higher frequencies though, as shown in Figure 9e'. This result is in good correlation with the glass transition values presented in Section 4.1. Given that the $10 \mathrm{wt} \%$ composite has the lowest $\mathrm{T}_{\mathrm{g}}$, the $\alpha$-relaxation process is initiated at lower temperatures, as compared to neat epoxy, and hence, the peak is shifted to slightly higher frequencies at $100{ }^{\circ} \mathrm{C}$.

Analogous to the observations made at $20^{\circ} \mathrm{C}$ (see Figure 8), at temperatures of $80{ }^{\circ} \mathrm{C}$ and below, the BDS analysis revealed similar $\varepsilon^{\prime}$ for neat epoxy, ePOSS $1 \mathrm{wt} \%$ and ePOSS $2.5 \mathrm{wt} \%$, while ePOSS $5 \mathrm{wt} \%$ and ePOSS $10 \mathrm{wt} \%$ exhibited steps in $\varepsilon^{\prime}$ in the low frequency domain (see Figures 9a to 9e). Those steps were much more distinct for the $10 \mathrm{wt} \%$ composite. According to these steps in $\varepsilon^{\prime}$, additional interfacial loss peaks in $\varepsilon^{\prime \prime}$ could be seen for ePOSS $5 \mathrm{wt} \%$ and ePOSS $10 \mathrm{wt} \%$, with higher magnitudes for the $10 \mathrm{wt} \%$ composite (Figure 9d' and Figure $\left.9 e^{\prime}\right)$. This interfacial loss peak was more difficult to detect at a temperature of $80^{\circ} \mathrm{C}$ in the case of ePOSS $5 \mathrm{wt} \%$ and it was 
a)

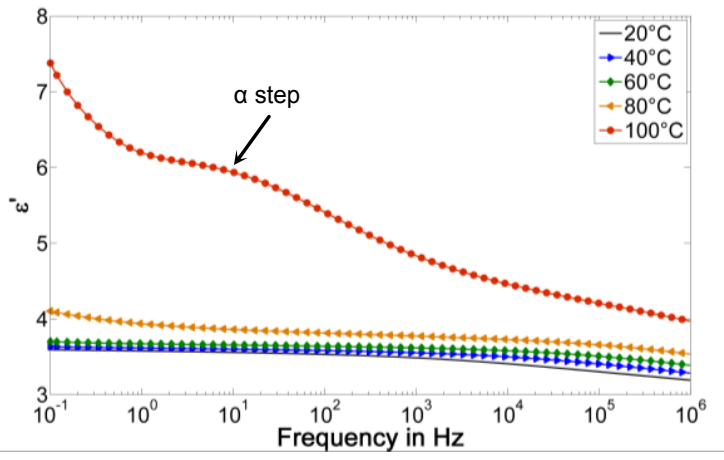

b)
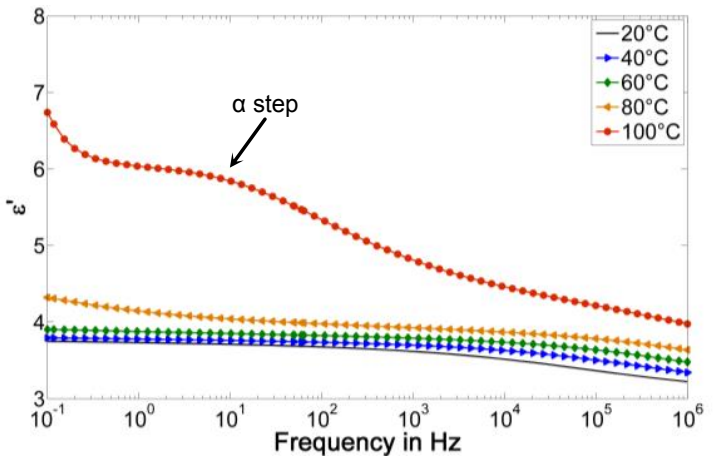

c)

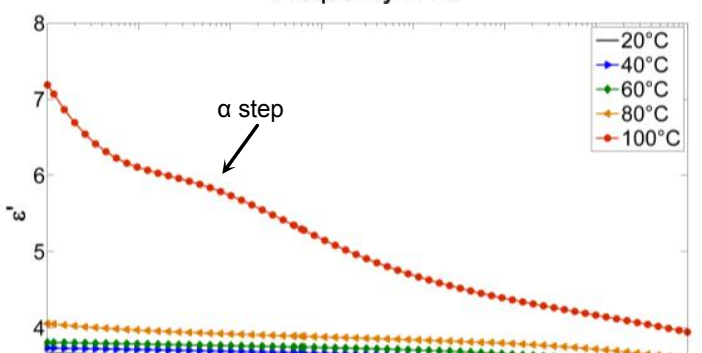

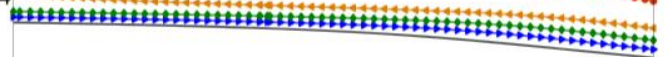

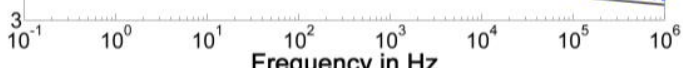

d)
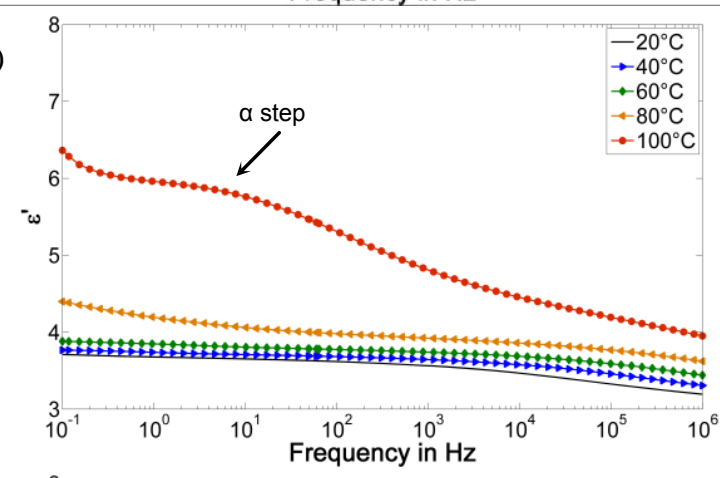

e)

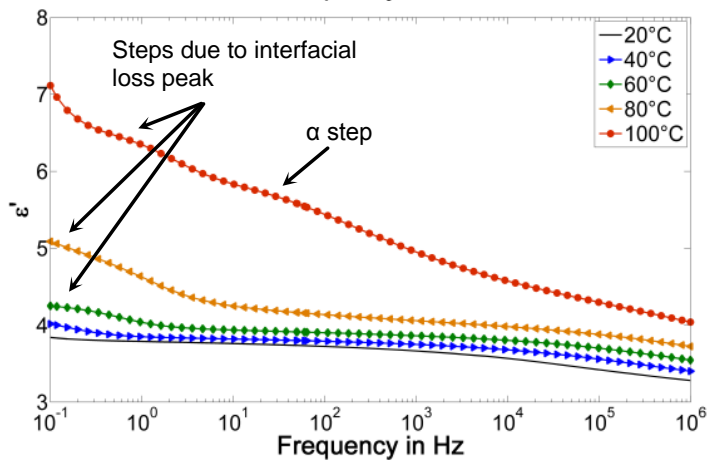

a')

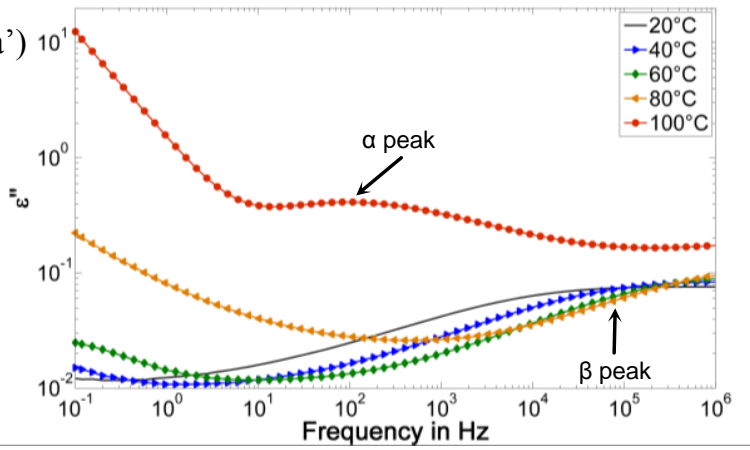

b') 10

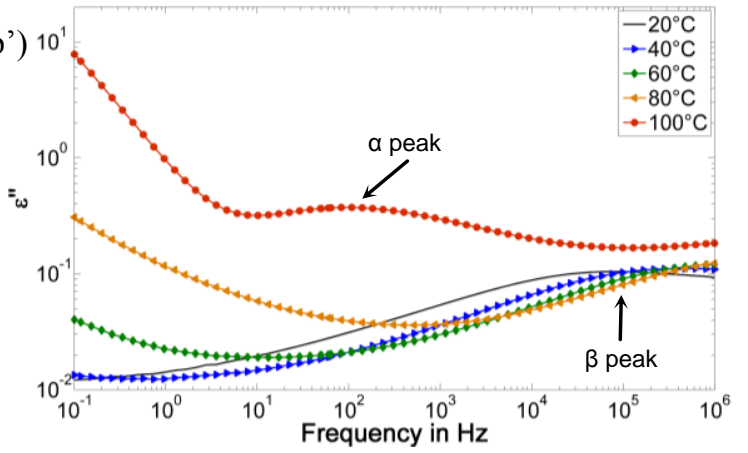

c')

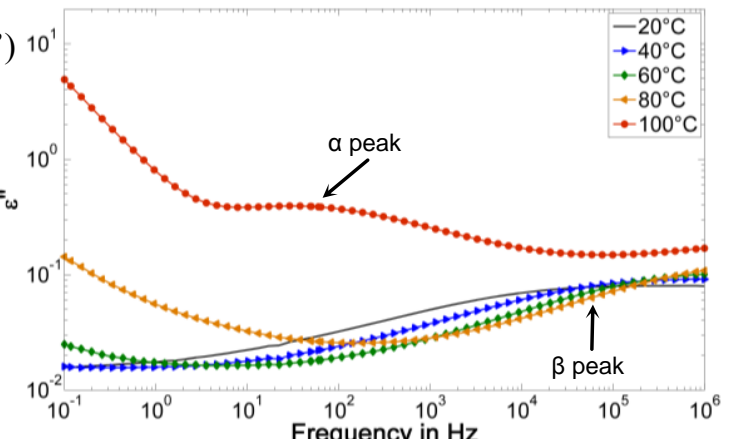

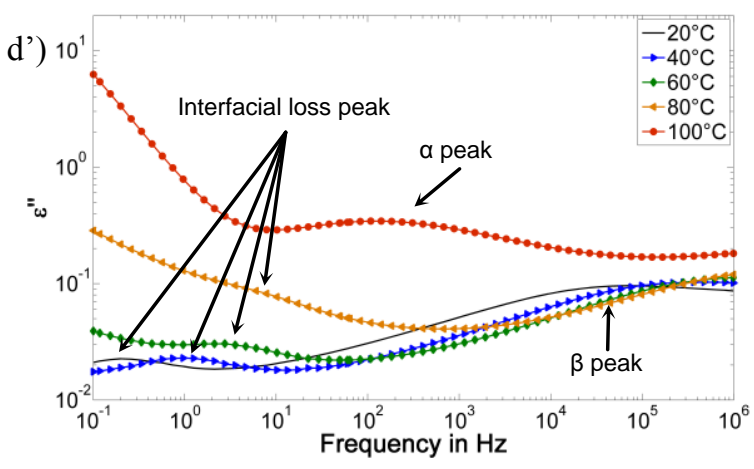

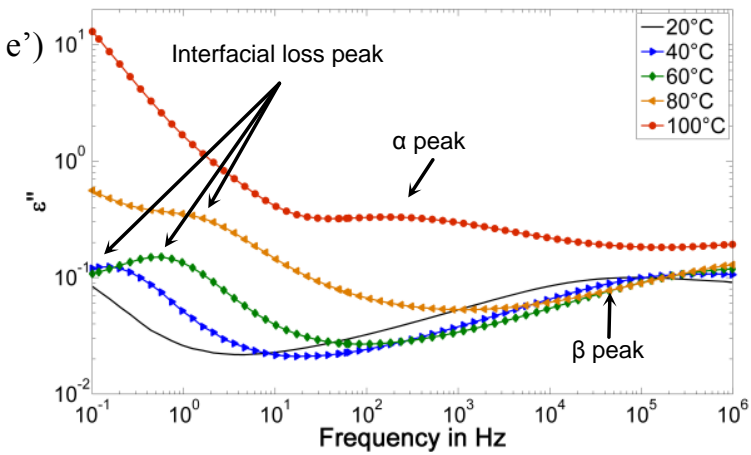

Figure 9. Temperature-dependent real part (left column) and imaginary part (right column) of complex permittivity for a) neat epoxy, b) ePOSS $1 \mathrm{wt} \%$, c) ePOSS $2.5 \mathrm{wt} \%$, d) ePOSS $5 \mathrm{wt} \%$ and e) ePOSS $10 \mathrm{wt} \%$ 
completely overshadowed by low-frequency dispersion due to charge fluctuations for a temperature of $100{ }^{\circ} \mathrm{C}$ for both, ePOSS 5wt $\%$ and ePOSS $10 \mathrm{wt} \%$. The increasing dielectric losses at $100{ }^{\circ} \mathrm{C}$ for lower frequencies with a slope $\neq-1$ on the $\log$-log scale, accompanied with the increasing real part of the permittivity for frequencies below $1 \mathrm{~Hz}$, translates a more complex behavior than simple DC conductivity of being responsible for the increasing dielectric losses [23]. The low frequency dispersion at $100{ }^{\circ} \mathrm{C}$ can be explained by interfacial polarization on a macroscopic level at the electrode/sample interface, the so called electrode polarization [36], possibly superimposed by electronic conductivity. This is a rather common behavior for solid insulating materials at elevated temperatures [5].

\subsection{RELAXATION BEHAVIOR}

For further understanding of the relaxation behavior of polymer composites, their dielectric responses are frequently fitted by an empirical equation (3) proposed by Havriliak and Negami [36], as it is known to be valid for polymers as well as inorganic materials:

$$
\varepsilon^{*}(\omega)=\varepsilon_{\infty}+\frac{\Delta \varepsilon}{\left(1+(i \omega \tau)^{\alpha_{H N}}\right)^{\beta_{H N}}}
$$

The frequency-dependent complex permittivity $\varepsilon^{*}(\omega)$ can be approximated by (3), where $\varepsilon_{\infty}$ is the high frequency permittivity, $\Delta \varepsilon$ the dielectric relaxation strength, $\omega$ the angular frequency $(\omega=2 \pi \cdot f), \tau$ the relaxation time, $\alpha_{\mathrm{HN}}$ and $\beta_{\mathrm{HN}}$ (with $0<\alpha_{\mathrm{HN}}<1$ and $\beta_{\mathrm{HN}}>0$ ) the Havriliak-Negami parameters which designate, respectively, the symmetric and asymmetric broadening of the relaxation time distribution function. When the shape parameters $\left(\alpha_{\mathrm{HN}}\right.$ and $\left.\beta_{\mathrm{HN}}\right)$ are equal to 1 , equation 3 is simplified, and the relaxation law proposed by Debye [37] is obtained.

In this study, the relaxation behavior of our test specimens was further analyzed by fitting the $\beta$-relaxation peaks of the imaginary part of the complex permittivity in order to obtain the corresponding relaxation times. After the corresponding relaxation times were obtained for all the investigated temperatures, the molecular mobility of polymer chains participating in the $\beta$-relaxation process was investigated, as described by the Arrhenius law:

$$
\tau=\tau_{0 \beta} \exp \frac{E_{a}}{k_{B} T}
$$

According to the Arrhenius law, the relaxation time $\tau_{\beta}$, which is inversely proportional to the molecular mobility, can be described with the pre-exponential factor $\tau_{0 \beta}$, the activation energy $E_{a}$ of the $\beta$-relaxation process and the Boltzmann's constant $\mathrm{k}_{\mathrm{B}}$. The global error, obtained after both the fitting of the $\beta$-relaxation and the derivation of the parameters of the Arrhenius law, was below $10 \%$.

The relaxation plots and activation energies for the samples are depicted in Figure 10 and Table 3, respectively. It can be seen that neat epoxy and all POSS composites, with the

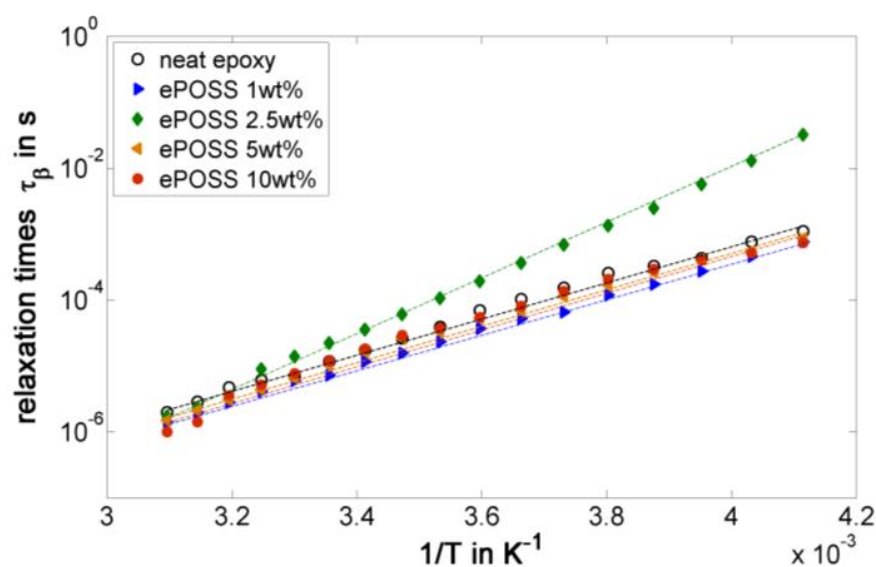

Figure 10. Relaxation time plots of the $\beta$-relaxation process

exception of the $2.5 \mathrm{wt} \%$ composite, show very similar $\beta$ relaxation behaviors and activation energies. However, ePOSS $2.5 \mathrm{wt} \%$ differs significantly, resulting in over $65 \%$ increased activation energy. This means, that by addition of $2.5 \mathrm{wt} \%$ POSS to the epoxy matrix, the molecular movements during the $\beta$-relaxation process are notably hindered. It appears that due to the good dispersion of POSS, along with the formation of covalent bonds between the filler and the epoxy, a more rigid epoxy/POSS network is obtained. Such an increase in the rigidity of the epoxy/POSS network is the result of incorporating the rigid silica-like cage structure of POSS into the matrix. However, if only $1 \mathrm{wt} \%$ POSS is added to the epoxy, this effect might not be that significant, and similarly, for the higher filler content composites with $5 \mathrm{wt} \%$ and $10 \mathrm{wt} \%$ POSS, where due to the formation of agglomerations not enough POSS could be integrated into the epoxy network, and hence, no distinct change in the rigidity of the molecular web resulted. These findings are supported by the aforementioned improvements in BD strength, erosion resistance and thermal conductivity, where the ePOSS $2.5 \mathrm{wt} \%$ composite out-performed neat epoxy and the other POSS composites, significantly in some cases.

Table 3. Activation energies obtained by fitting the $\beta$-relaxation process.

\begin{tabular}{c|c}
\hline Sample type & $\mathrm{E}_{\mathrm{a}}$ in eV \\
\hline Neat epoxy & 0.526 \\
ePOSS 1wt\% & 0.526 \\
ePOSS $2.5 \mathrm{wt} \%$ & 0.875 \\
ePOSS 5wt $\%$ & 0.523 \\
ePOSS 10wt $\%$ & 0.504 \\
\hline
\end{tabular}

\section{CONCLUDING REMARKS}

The aim of this study was to investigate the dielectric and thermal properties of epoxy/POSS composites, along with the effect of nanostructurization of composites, by incorporating a reactive TGIB-POSS and dispersing it at a molecular level.

It has been shown that the addition of low amounts of TGIB-POSS $(\leq 5 \mathrm{wt} \%)$ leads to significantly improved dielectric breakdown strengths, corona resistances, as well as thermal conductivities of the resulting epoxy/POSS composites. It is assumed that the formation of covalent bonds 
between the filler and the epoxy matrix significantly improves the filler/matrix interaction, leading to intimate interfaces instead of undefined interphases, and hence, contributes to a distinct improvement in performance for the resulting composites. This is supported by the superior performances of the lower content composites ePOSS $1 \mathrm{wt} \%$ and ePOSS $2.5 \mathrm{wt} \%$, where no agglomerations were found, and hence, the dispersion of POSS at a molecular level in the epoxy has been successfully achieved.

In conclusion, although we used a reactive additive, agglomerations could not be avoided for higher filler contents. This prohibited the incorporation of a larger POSS content in the epoxy network, which should be beneficial for further improvements in dielectric performance, such as the resistance to corona discharges. The limited dissolubility of the used TGIB-POSS in epoxy can be attributed to its low degree of reactivity (only 3 epoxy side groups around the silica-like core). In fact, when a different POSS additive with a higher degree of reactivity, and hence, a higher amount of epoxy sidegroups, was used to fabricate epoxy composites, we successfully incorporated even larger contents of POSS into the epoxy matrix, without finding agglomerations. Consequently, the corona resistance of these composites could be enhanced even more significantly [14].

\section{ACKNOWLEDGMENT}

Hydro-Québec and the Natural Sciences and Engineering Research Council of Canada (NSERC) are gratefully recognized for their financial support.

\section{REFERENCES}

[1] M. F. Fréchette, M. Trudeau, H. D. Alamdari, and S. Boily, "Introductory remarks on nanoDielectrics," IEEE Conf. Electr. Insul. Dielectr. Phenomena, Kitchener, ON, Canada, 2001, pp. 92-99, 2001.

[2] J. K. Nelson and ed., Dielectric Polymer Nanocomposites: Springer Science+Business Media, 2010.

[3] M. Dongling, A. H. Treese, W. S. Richard, A. Christerson, E. Martensson, C. Önneby, L. S. Schadler, "Influence of nanoparticle surface modification on the electrical behaviour of polyethylene nanocomposites," Nanotechnology, Vol. 16, pp. 724-731, 2005.

[4] X. Huang, T. lizuka, P. Jiang, Y. Ohki, and T. Tanaka, "Role of Interface on the Thermal Conductivity of Highly Filled Dielectric Epoxy/AlN Composites," J. Phys. Chem. C, Vol. 116, pp. 13629-13639, 2012/06/28 2012.

[5] I. Preda, J. Castellon, S. Agnel, H. Couderc, M. Fréchette, F. Gao, R. Nigmatullin, S. Thompson, A. F. Vaessen, "Dielectric response of various partially cured epoxy nanocomposites," IEEE Trans. Dielectr. Electr. Insul., Vol. 20, pp. 580-591, 2013.

[6] S. Virtanen, T. M. Krentz, J. K. Nelson, L. S. Schadler, M. Bell, B. Benicewicz, et al., "Dielectric breakdown strength of epoxy bimodalpolymer-brush-grafted core functionalized silica nanocomposites," IEEE Trans. Dielectr. Electr. Insul., Vol. 21, pp. 563-570, 2014.

[7] J. Bocek, L. Matejka, V. Mentlik, P. Trnka, and M. Slouf, "Electrical and thermomechanical properties of epoxy-POSS nanocomposites," European Polymer J., Vol. 47, pp. 861-872, 2011.

[8] J. Chen, Nanostructuration of epoxy networks by using polyhedral oligomeric silsesquioxanes POSS and its copolymers, Ph.D. degree thesis, École Doctorale des Matériaux I. M. P. Ingénierie des Matériaux Polymères, Institut national des sciences appliquées, Lyon, 2012.

[9] S.-W. Kuo and F.-C. Chang, "POSS related polymer nanocomposites," Progress in Polymer Science (Oxford), Vol. 36, pp. 1649-1696, 2011.
[10] J. Horwath, D. Schweickart, G. Garcia, D. Klosterman, and M. Galaska, "Improved performance of polyhedral oligomeric silsesquioxane epoxies," IEEE Conf. Electr. Insul. Dielectr. Phenomena, pp. 155-157, 2005.

[11] T. Heid, M. Fréchette, and E. David, "Nanostructured Epoxy/POSS composites: High Performance Dielectrics with Improved Corona Resistance and Thermal Conductivity," IEEE Electr. Insul. Conf. (EIC), pp. 316-319, 2014.

[12] X. Huang, Y. Li, F. Liu, P. Jiang, T. lizuka, K. Tatsumi, et al., "Electrical properties of epoxy/POSS composites with homogeneous nanostructure," IEEE Trans. Dielectr. Electr. Insul., Vol. 21, pp. 1516$1528,2014$.

[13] J. C. Horwath, D. L. Schweickart, G. Garcia, D. Klosterman, M. Galaska, A. Schrand, et al., "Improved electrical properties of epoxy resin with nanometer-sized inorganic fillers," IEEE $27^{\text {th }}$ Int'l. Power Modulator Conf. (IPMC) and High Voltage Workshop, Washington, DC, USA, pp. 189-191, 2006.

[14] T. Heid, M. Fréchette, and E. David, "Nanostructured Epoxy/POSS composites: High Performance Dielectrics with Improved Breakdown Strength and Corona Resistance," IEEE Conf. Electr. Insul. Dielectr. Phenomena (CEIDP), pp. 659-662, 2014.

[15] M. Takala, M. Karttunen, J. Pelto, P. Salovaara, T. Munter, M. Honkanen, et al., "Thermal, mechanical and dielectric properties of nanostructured epoxy-polyhedral oligomeric silsesquioxane composites," IEEE Trans. Dielectr. Electr. Insul., Vol. 15, pp. 1224$1235,2008$.

[16] L. Yang, M. Yin, X. Li, and H. Ma, "Thermal and dielectric properties of inorganic-organic nanocomposites involving epoxy resin and polyhedral oligomeric silsesquioxanes," 3rd Int'l. Conf. Manufacturing Sci. Engineering (ICMSE), Xiamen, China, pp. 665-669, 2012.

[17] T. F. Heid, M. Fréchette, and E. David, "Dielectric Properties of Epoxy/POSS composites," IEEE Conf. Electr. Insul. Dielectr. Phenomena (CEIDP), pp. 751-755, 2013.

[18] ASTM-International, "ASTM D149 - 09: Standard Test Method for Dielectric Breakdown Voltage and Dielectric Strength of Solid Electrical Insulating Materials at Commercial Power Frequencies," ed. West Conshohocken, PA, USA, 2013.

[19] ASTM-International, "ASTM E1530 - 11: Standard Test Method for Evaluating the Resistance to Thermal Transmission of Materials by the Guarded Heat Flow Meter Technique," ed, 2011.

[20] J. S. Nakka, "Tailoring of epoxy material properties," Ph.D. thesis, Mechanical, Maritime and Materials Engineering, Delft University of Technology, Delft, 2010.

[21] "IEEE Std 930-2004: IEEE Guide for the Statistical Analysis of Electrical Insulation Breakdown Data," ed. New York, NY: IEEE, 2004.

[22] P. Preetha and M. J. Thomas, "AC breakdown characteristics of epoxy nanocomposites," IEEE Trans. Dielectr. Electr. Insul., Vol. 18, pp. $1526-1534,2011$.

[23] G. Iyer, R. S. Gorur, R. Richert, A. Krivda, and L. E. Schmidt, "Dielectric properties of epoxy based nanocomposites for high voltage insulation," IEEE Trans. Dielectr. Electr. Insul., Vol. 18, pp. 659-666, 2011.

[24] C. Zou, J. C. Fothergill, and S. W. Rowe, "The effect of water absorption on the dielectric properties of epoxy nanocomposites," IEEE Trans. Dielectr. Electr. Insul., Vol. 15, pp. 106-117, 2008.

[25] J. Laskowski and J. A. Kitchener, "The hydrophilic-hydrophobic transition on silica," J. Colloid and Interface Sci., Vol. 29, pp. 670-679, 1969.

[26] T. Tanaka, Y. Matsuo, and K. Uchida, "Partial Discharge Endurance of Epoxy / SiC Nanocomposite," IEEE Conf. Electr. Insul. Dielectr. Phenomena (CEIDP) pp. 13-16, 2008.

[27] M. Brockschmidt, F. Pohlmann, S. Kempen, and P. Groppel, "Testing of nano-insulation materials: Some ideas, some experiences," IEEE Electr. Insul. Conf. (EIC), pp. 506-510, 2011.

[28] M. Kozako, S. Kuge, T. Imai, T. Ozaki, T. Shimizu, and T. Tanaka, "Surface erosion due to partial discharges on several kinds of epoxy nanocomposites," IEEE Electr. Insul. Dielectr. Phenomena CEIDP), pp. 162-165, 2005.

[29] Y. Takezawa, M. Akatsuka, and C. Farren, "High thermal conductive epoxy resins with controlled high order structure," IEEE $7^{\text {th }}$ Int'l. Conf. Properties and Applications of Dielectric Materials (ICPADM), Vol. 3, pp. 1146-1149, 2003. 
[30] W. Cui, F. Du, J. Zhao, W. Zhang, Y. Yang, X. Xie, M. Yiu-Wing, "Improving thermal conductivity while retaining high electrical resistivity of epoxy composites by incorporating silica-coated multiwalled carbon nanotubes," Carbon, Vol. 49, pp. 495-500, 2011.

[31] T. Heid, M. Fréchette, and E. David, "Epoxy/BN Micro- and SubmicroComposites: Dielectric and Thermal Properties of Enhanced Materials for High Voltage Insulation Systems," IEEE Trans. Dielectr. Electr. Insul., Vol. 22, No. 2, 2015.

[32] T. Heid, M. Fréchette, and E. David, "Dielectric and Thermal Properties of Submicrometric Epoxy/c-BN Composites," IEEE Conf. Electr. Insul. Dielectr. Phenomena (CEIDP), pp 719-722, 2014.

[33] R. Kochetov, T. Andritsch, U. Lafont, P. H. F. Morshuis, and J. J. Smit, "Thermal conductivity of nano-filled epoxy systems," IEEE Conf. Electr. Insul. Dielectr. Phenomena (CEIDP), pp. 658-661, 2009.

[34] M. Fréchette, I. Preda, J. Castellon, A. Krivda, R. Veillette, M. Trudeau, E. David, "Polymer composites with a large nanofiller content: a case study involving epoxy," IEEE Trans. Dielectr. Electr. Insul., Vol. 21, pp. 434-443, 2014.

[35] J. Y. Lee, Y. W. Song, S. W. Kim, and H. K. Lee, "Dielectric and molecular dynamic studies of sub-Tg by thermally stimulated current (TSC) analysis for liquid crystalline epoxy thermosets," Materials Chem. Phys., Vol. 77, pp. 455-460, 1/15/ 2003.

[36] F. S. A. Kremer, Broadband dielectric spectroscopy. Berlin; New York: Springer, 2003.

[37] G. G. Raju, Dielectrics in Electric Fields, New York, USA: Marcel Dekker, 2003.

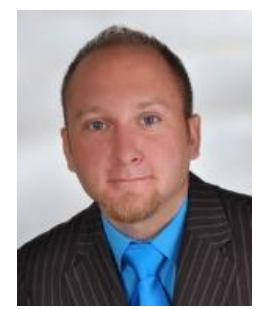

Thomas Heid (S'10) studied electrical engineering at Graz University of Technology (Austria) where he graduated with an M.Sc. (2011) degree, specializing in high voltage engineering. He was a project assistant at the Institute of High Voltage Engineering and System Management and the Test Institute of High Voltage Engineering (Graz, Austria) until 2012, where he has been involved in numerical calculations for high voltage cable systems, life cycle analysis for stator bars, as well as high voltage testing of electrical equipment. Currently he is a Ph.D. candidate with the Hydro-Québec Research Institute (IREQ) in cooperation with the École de Technologie Supérieure (ETS). His main research interest is the development of nanodielectrics for application in high voltage insulation systems.

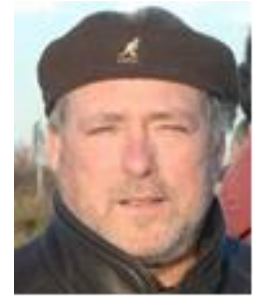

Dr. Michel Fréchette has a graduate degree in physics. He joined Hydro-Québec's Research Institute (IREQ) in the $20^{\text {th }}$ century. Since then, he has been involved in applied basic research in various fields related to electrical insulation and insulating materials. His major contributions involve discharge physics, dielectric phenomena and nanodielectrics.

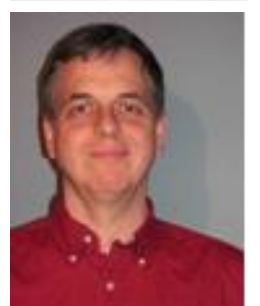

Eric David (M'03, SM'07) was born in Montreal in 1965. He received the M.Sc.A and Ph.D. degrees in Engineering Physics from the École Polytechnique de Montréal in 1989 and 1996, respectively. He joined the Hydro-Québec Research Institute (IREQ) in 1998, and from 2001 to 2002 , where he was active in the field of dielectric materials used for underground cables and rotating machines. He is now a Professor at the Department of Mechanical Engineering in the École de Technologie Supérieure (ETS) in Montreal. His research interests include dielectric and nanodielectric materials, rotating machinery and underground cable insulation. $\mathrm{He}$ is an Associate Editor of the IEEE Transactions on Dielectrics and Electrical Insulation. 